\section{Total Synthesis of Protected L-Galactose by Hydrocarbon Oxidation}

Metal-Catalyzed Asymmetric Synthesis and Stereoselective

Reactions

\section{Key words}

hydrocarbons

oxidation

palladium<smiles>C=CCC(OCc1ccccc1)C1COC(C)(C)O1</smiles>

$\mathrm{Pd}(\mathrm{OAc})_{2}(10 \mathrm{~mol} \%)$ DMSO- $\mathrm{CH}_{2} \mathrm{Cl}_{2}(2 \mathrm{M})$ DIPEA (50 mol\%)<smiles>COc1ccc(C(=O)OC/C=C/C(OCc2ccccc2)C2COC(C)(C)O2)cc1</smiles>
air $41^{\circ} \mathrm{C}$

\section{$75 \%$ yield}

$>300: 1$ linear/branched $97: 3 E / Z$

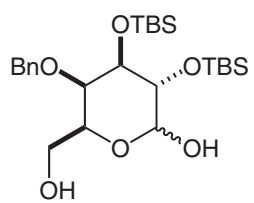

protected L-galactose
Significance: Following on their work on DMSOpromoted, $\mathrm{Pd}(\mathrm{OAc})_{2}$-catalyzed allylic oxidation reactions (M. S. Chen, M. C. White J. Am. Chem. Soc. 2004, 126, 1346-1347), the authors proved that no erosion of enantiomeric purity was observed in the course of their methodology when using an enantioenriched alkene (Org. Lett. 2005, 7, 223-226). In the present paper, they describe their recent achievements towards the rapid synthesis of polyol frameworks. In particular, they report on the total synthesis of protected L-galactose.
Comment: Initial reaction conditions were carefully optimized to allow the stereo- and regioselective allylic oxidation of an $\alpha$-chiral olefin using $p$ anisic acid. Addition of a noncoordinating base and use of phenylbenzoquinone instead of benzoquinone both increased the yield of the reaction. Interestingly, the acetonide protecting group within the chiral moiety proved to be stable under the reaction conditions. The linear product was obtained predominantly over the branched analogue (>300:1) and could be further derivatized to yield the enantioenriched protected L-galactose in five steps. The two remaining stereogenic centers were installed by Sharpless asymmetric dihydroxylation.

SYNFACTS Contributors: Mark Lautens, Yann Béthuel 